\title{
Study on Integration Schedule of the Spatial of Regional Logistics Based on Principle Component and Two-dimension Graphics Cluster Analysis
}

\author{
Case Study in Shanxi Province
}

\author{
Chunju Jing* \\ Management Science and Engineering \\ Shanxi University of Finance and Economics \\ Taiyuan, China \\ jcj200168@163.com
}

\author{
Yuyang Jing \\ Senior High School Department \\ Taiyuan zhida Ivy Middle School \\ Taiyuan, China
}

\begin{abstract}
The paper constructed the comprehensive evaluation index system via selecting 10 indexes: consumption demand and infrastructure. Adopted principle component to make the initial Regional Logistics Space Integration (RLSI) schedule of Shanxi Province, then employed two-dimensional graphics cluster in determining the core and dividing integration layers, extracting the latitude and longitude coordinates of every municipal government resident and combining them with the principle component scores, and made the finishing schedule by ranking the principle component and referencing the realistic situation. Results could divide into three circles centered around the Taiyuan City, Datong City, Linfen City. Circle A includes Taiyuan City, Jinzhong City, Xinzhou City, Shuozhou City, Lvliang City; Circle B includes Datong City, Yangquan City, Changzhi City, Jincheng City; Circle $\mathrm{C}$ includes Linfen City, Yuncheng City. The study can be the basis of decision for carrying out the(RLSI) .
\end{abstract}

Keywords-RLSI; Principle component analysis; Twodimension graphicscluster analysis; Shanxi province

The RLSI, With respect to time, it's necessary to correlate the construction of logistics facilities in city area in the previous period, and explore the future development direction and preference of the city in various directions; with respect to space, it's necessary not only to take care of the needs of the development of logistics in different cities, but also to consider the spatial level of the boundaries of the region[1]. The time sequence of RLSI has a direct impact on how to adapt to local conditions, organization, consideration of the planning of logistics parks in different regions and the constructing logistics nodes.

Academic research on regional logistics is carried out earlier in foreign countries, mainly from the micro scale, focusing on the relationship between logistics and economic development, regional logistics impact mechanism, logistics system planning, logistics node integration and other issues[25]. The research on RLSI begins relatively to be late in China. such as the method for industrial integration effect, the concept of logistics industry integration, and etc. [6] In addition, the research of spatial scale is mainly about urban conglomeration and focuses on the spatial distribution characteristics of the logistics industry. The research methods are often combined with GIS and Geordie Coefficient, location entropy, and gravity models [7-10], and the regions are mainly concentrated in the "Yangtze River Delta" region. In summary, the academic circles explore a little about the RLSI.

In the current practice of RLSI, It has neglected to gradually advance from timing, region, and classification. There are 754 logistics facilities, scattered in various regions in Shanxi Province, It's indicated the necessity of this research. In view of this, the paper constructs a comprehensive evaluation index system for regional logistics, and integrates non-spatial principal component analysis and spatial two-dimensional graphics cluster analysis logically and precisely. Exploring the time sequence of regional logistics spatial integration in Shanxi province.Not only considers the overall conditions of the evaluation unit, but also ensures spatial coherence and geographical orientation, Taking the region as an evaluation unit and exploring the logistics integration timing on a small scale is more operational. It expand the theory of RLSI, provide scientific decision-making basis for the development of RLSI in Shanxi Province.

\section{OVERVIEW OF RESEARCH AREA AND DATA SOURCES}

\section{A. Overview of Research Area}

The study area includes 11 region such as Taiyuan, Datong, Yangquan, Changzhi, Jincheng, Shuozhou, Xinzhou, Lvliang, Jinzhong, Linfen and Yuncheng. The geographic coordinates are $34^{\circ} 34^{\prime}-40^{\circ} 44^{\prime}$ north latitude and $110^{\circ} 14^{\prime}-114^{\circ} 33^{\prime}$ east longitude.

\section{B. Data Acquisition and Organization}

The latitude and longitude coordinates of the local cities in Shanxi Province are derived from Baidu maps. The remaining data, except where specifically stated, are derived from the 2015 Statistical Yearbook of Shanxi, the statistical yearbooks of various cities in Shanxi Province in 2015, and the "National Economic Development and Social Development Statistics Announcement" of 2016 in various cities. 


\section{CONSTRUCTION AND RESEARCH METHODS OF INDEX SYSTEM}

\section{A. Index System Construction}

The construction of evaluation indicators is an important step in the sequential exploration of RLSI. Basing on the literature [8-12], building the following evaluation indicators (Table I).

\section{B. Research Methods}

- Principal component analysis. Refers to a statistical analysis method the by processing of multiple indicators into a few comprehensive indicators and as much as possible to show the original indicators of information to obtain independence between the main components, to simplify analysis structure. It can be used as an appropriate choice to deal with regional logistics integration problems.

- Two-dimensional graphics cluster analysis. It classifies a group of samples or variables according to their intimacy of properties and then considers spatial adjacency according to the geometry concept of graph theory. At the same time, it is more important to consider the inherent similarities between the partition units. Among them, spatial adjacency represents the geographic location information, and internal similarity represents the degree of similarity in demand for social consumer goods and infrastructure investment.

\section{RESULTS AND CORRELATION ANALYSIS}

\section{A. Initial Sequence of Regional Logistics Integration}

Select SPSS19.0 software, following the principle that the eigenvalue is greater than 1 and the contribution rate of principal component accumulation is not less than $80 \%$. The two main factors are extracted (Table II), obtaining a comprehensive score for the RLSI (Table III).

From Table available: X1 and X8 have a higher load on factor 1, mainly reflecting the demand for social consumer goods in the region; X7 has a larger load on factor 2, mainly reflecting the investment in logistics infrastructure. Two primary components, the economic development level and the logistics infrastructure factor, were extracted to replace the original 10 variables. Among them, the contribution rate of social consumer goods demands factor reached $70.86 \%$, which was far greater than the contribution rate of logistics infrastructure. This shows that integration of regional logistics in Shanxi Province is still linked to the demand for social consumer goods.

From Table III, among the 11 prefecture-level region in Shanxi Province, the dominant factor in Taiyuan and Datong areas is social consumer goods. The overall score is 5.8902237 and 0.0895005 . One reason is that the coal industry has a single structure, which means that light industrial goods and fastmoving consumer goods in the province can only be imported from outside the province; another reason is that tourism in Datong and Taiyuan has become a pillar industry, which has led to a rise in consumer goods. At the end of 2016, the total retail sales of consumer goods in Taiyuan amounted to RMB 166.624 billion, which had an increase of $8.1 \%$ over the previous year. In the same year, the total retail sales of consumer goods in Datong City were 60.90 billion yuan, which had an increase of $7.3 \%$ over the previous year. The rapid growth of consumer goods in the two cities shows that the proportion of the coal industry in the GDP of the two cities had a downward trend.

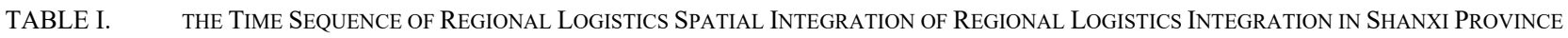

\begin{tabular}{|c|c|c|c|c|c|c|c|c|c|c|}
\hline $\begin{array}{l}\text { Region } \\
\text { Name }\end{array}$ & $\begin{array}{c}\mathbf{X}_{1} \\
\text { region } \\
\text { GDP } \\
(\mathbf{1 0} \\
\mathbf{K} \\
\text { yuan } \\
\stackrel{)}{ }\end{array}$ & $\begin{array}{c}X_{2} \text { Per } \\
\text { Capita } \\
\text { GDP } \\
(\text { yuan } \\
\text { ) }\end{array}$ & $\begin{array}{c}\mathbf{X}_{3} \text { gross } \\
\text { industri } \\
\text { al } \\
\text { output } \\
\text { value } \\
(10 \mathrm{~K} \\
\text { yuan) }\end{array}$ & $\begin{array}{c}X_{4} \text { gross } \\
\text { agricultur } \\
\text { al output } \\
(10 \mathrm{~K} \\
\text { yuan) }\end{array}$ & $\begin{array}{l}X_{5} \text { total } \\
\text { retail of } \\
\text { consume } \\
\text { r goods } \\
(10 K \\
\text { yuan) }\end{array}$ & $\begin{array}{c}\begin{array}{c}X_{6} \\
\text { gross }\end{array} \\
\text { import } \\
\text { and } \\
\text { export } \\
(10 K \\
\text { yuan })\end{array}$ & $\begin{array}{c}\mathrm{X}_{7} \\
\text { highway } \\
\text { mileage } \\
\text { (Kilom } \\
\text { eter) }\end{array}$ & 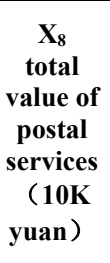 & $\begin{array}{c}\mathbf{X}_{9} \\
\text { number } \\
\text { of } \\
\text { Internet } \\
\text { users } \\
\text { (10K } \\
\text { family) }\end{array}$ & $\begin{array}{c}\mathrm{X}_{10} \\
\text { number } \\
\text { of } \\
\text { mobile } \\
\text { phone } \\
\text { users } \\
(10 K f \\
\text { amily) }\end{array}$ \\
\hline Taiyuan & $\begin{array}{l}2955 . \\
6\end{array}$ & 68438 & 9328587 & 154555 & $\begin{array}{l}1429803 \\
3\end{array}$ & $\begin{array}{l}106773 \\
7\end{array}$ & 7348 & 122932 & 150.79 & 742.66 \\
\hline Datong & $\begin{array}{l}1025 . \\
34\end{array}$ & 30101 & 3871704 & 120206 & 4218082 & 41633 & 12541 & 33803 & 49.76 & 342.37 \\
\hline Yangquan & 622.9 & 44547 & 1760958 & 22020 & 2098307 & 20489 & 5648 & 14985 & 31.32 & 151.78 \\
\hline Changzhi & $\begin{array}{l}1296 . \\
2\end{array}$ & 37896 & 1541219 & 35533 & 3463178 & 15733 & 11346 & 22594 & 55.36 & 298.78 \\
\hline Jincheng & $\begin{array}{l}1049 . \\
3\end{array}$ & 45327 & 835087 & 8900 & 1897564 & 89597 & 8961 & 15167 & 39.3 & 224.7 \\
\hline Shuozhou & 916 & 51980 & 1974739 & 158881 & 1314128 & 5866 & 10163 & 12209 & 20.5 & 182.06 \\
\hline Xinzhou & 716.1 & 22796 & 303123 & 86357 & 828163 & 19501 & 15839 & 25264 & 51.14 & 296.29 \\
\hline Lvliang & 995.3 & 25972 & 185030 & 18751 & 629783 & 40549 & 15984 & 35338 & 72.4 & 425.7 \\
\hline Jinzhong & $\begin{array}{l}1091 . \\
1\end{array}$ & 32710 & 655394 & 194325 & 911994 & 20650 & 17340 & 27375 & 36.5 & 270.5 \\
\hline Linfen & $\begin{array}{l}1205 . \\
2 \\
\end{array}$ & 27171 & 556785 & 91336 & 2259381 & 30160 & 18114 & 31891 & 64.49 & 397.14 \\
\hline
\end{tabular}


TABLE II. FACTOR LOADING MATRIX, EIGENVALUES AND CONTRIBUTION RATES

\begin{tabular}{|l|c|c|l|}
\hline & Factor 1 & Factor 2 & \multicolumn{1}{|c|}{ Factor 3 } \\
\hline $\mathrm{X}_{1}$ & 0.3621814 & 0.1023735 & -0.005159058 \\
\hline $\mathrm{X}_{2}$ & 0.2681587 & -0.464909 & 0.254106058 \\
\hline $\mathrm{X}_{3}$ & 0.3550815 & -0.128426 & 0.153023496 \\
\hline $\mathrm{X}_{4}$ & 0.1197021 & 0.3402957 & 0.86093509 \\
\hline $\mathrm{X}_{5}$ & 0.3692987 & -0.052542 & -0.001093123 \\
\hline $\mathrm{X}_{6}$ & 0.3695679 & 0.0015842 & -0.013013561 \\
\hline $\mathrm{X}_{7}$ & -0.150576 & 0.7000407 & -0.010843727 \\
\hline $\mathrm{X}_{8}$ & 0.3655764 & 0.1399685 & -0.075383336 \\
\hline $\mathrm{X}_{9}$ & 0.3439871 & 0.1882481 & -0.319846193 \\
\hline $\mathrm{X}_{10}$ & 0.3299936 & 0.3053467 & -0.250011413 \\
\hline Eigenvalues & 7.0858406 & 1.6889297 & 0.945978291 \\
\hline $\begin{array}{l}\text { Contribution } \\
(\%)\end{array}$ & 70.858406 & 16.889297 & 9.459782908 \\
\hline $\begin{array}{l}\text { Cumulative Contribution } \\
\text { Rate (\%) }\end{array}$ & 70.858406 & 87.747703 & 97.20748629 \\
\hline
\end{tabular}

TABLE III. PRINCIPAL COMPONENT SCORES AND COMPREHENSIVE EVALUATION VALUES AROUND CITIES IN SHANXI PROVINCES

\begin{tabular}{|l|l|l|l|l|}
\hline Name & $\begin{array}{c}\text { Social } \\
\text { consumer } \\
\text { goods } \\
\text { demand } \\
\text { factor }\end{array}$ & $\begin{array}{c}\text { Infrastructure } \\
\text { investment } \\
\text { factor }\end{array}$ & $\begin{array}{c}\text { Comprehensive } \\
\text { evaluation } \\
\text { value }\end{array}$ & Sorting \\
\hline Taiyuan & 8.3211551 & -0.062759 & 5.8902237 & 1 \\
\hline Datong & 0.0433646 & 0.2072507 & 0.0895005 & 2 \\
\hline Yangquan & -1.234651 & -2.500298 & -1.325922 & 11 \\
\hline Changzhi & -0.36861 & -0.664939 & -0.441993 & 6 \\
\hline Jincheng & -0.923134 & -1.728061 & -1.005272 & 10 \\
\hline Shuozhou & -0.951562 & -1.20133 & -0.692785 & 8 \\
\hline Xinzhou & -1.533814 & 0.8725288 & -0.973799 & 9 \\
\hline Lvliang & -0.819348 & 0.8984278 & -0.580916 & 7 \\
\hline Jinzhong & -1.073984 & 1.3044541 & -0.387185 & 5 \\
\hline Linfen & -0.58731 & 1.4930643 & -0.205911 & 3 \\
\hline Yuncheng & -0.872107 & 1.3816617 & -0.36594 & 4 \\
\hline
\end{tabular}

${ }^{\text {a. }}$ Infrastructure input factor plays a major role in Linfen and Yuncheng, with a combined score of 1.4930643 kilometers, of which expressway was 462 kilometers; Yuncheng's highway mileage was 16,085
kilometers including 598 kilometers of expressway.

\section{B. Division of Regional Logistics Integration Circle Layer}

In the DPS data processing system, the names of 11 prefecture-level region in Shanxi Province are arranged vertically. Horizontal latitude and longitude coordinates of local government offices and the two principal component scores extracted from principal component analysis are arranged horizontally to obtain a two-dimensional data table. The cluster graph was formed using the two-dimensional graph theory clustering tool in the cluster analysis under the multivariate analysis menu. Using GIS software to transfer the relationship between the points and lines in the map to the geographic spatial orientation, and then added to the administrative map data layer, to get the two-dimensional graph theory cluster analysis chart of Shanxi province regional logistics integration (As shown in Fig. 1).

The points directly connected on the line in the twodimensional graph theory cluster analysis show areas where the overall conditions in all aspects have certain similarities. From the figure, the comprehensive conditions of Jinzhong, Xinzhou, Shuozhou, and Lvliang have similarities in all aspects and can be transformed into a circle layer. Considering Taiyuan, which ranks first in comprehensive ranking of the principal components, it is geographically close to these four cities. Therefore, Taiyuan is painted in this circle as the center point of the sub-circle, and Jinzhong is the secondary center point. Datong, Yangquan, Changzhi, and Jincheng are all linked with straight lines. According to the principle of two-dimensional graph theory clustering, we can see that the comprehensive conditions of these four cities have certain similarities and can be drawn in a circle. According to the comprehensive ranking of principal components, Datong (ranked second) can be taken as the center point, and Changzhi as the secondary center point; the remaining Linfen and Yuncheng can be turned into a circle, and both cities are dominated by infrastructure input factors, that shows that the comprehensive conditions have very high similarities. According to the comprehensive rankings of the principal components, Linfen ranks third and Yuncheng is the fourth, so Linfen is chosen as the center point of this circle. Therefore, the circle of regional logistics integration in Shanxi Province is: A layer (Taiyuan City, Jinzhong City, Xinzhou City, Shuozhou City, Lvliang City), B layer (Datong City, Yangquan City, Changzhi City, Jincheng City), C layer (Linfen City, Yuncheng City), the center points of these three circles are Taiyuan, Datong and Linfen respectively. In the "Mid-term and long-term plan for the development of the national logistics industry," Taiyuan, Datong, and Linfen in Shanxi Province are classified into logistics second-node cities at the national level. Based on this, it can be concluded that based on the principal component analysis method, the determination of the center points in the circle of integration with the twodimensional graph theory cluster analysis is scientific.
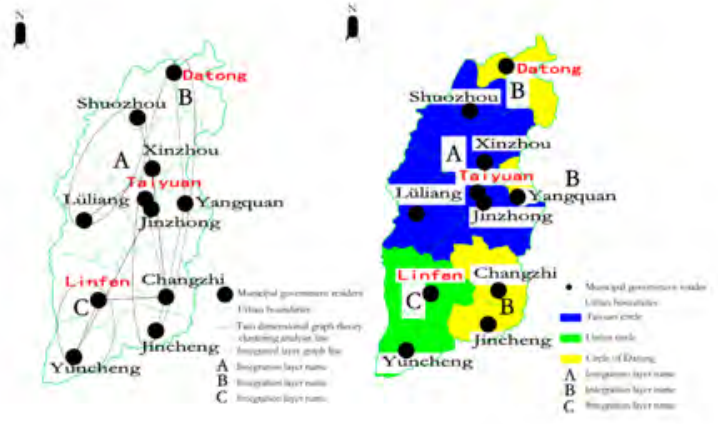

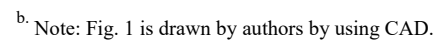

Fig. 1. Shanxi province regional logistics integration sequence twodimensional graph theory cluster analysis chart.

\section{Determination of RLSI}

According to Table III, the comprehensive scores of center points in each circle are Taiyuan $>$ Datong $>$ Linyi. The circle A with Taiyuan as the center is the central area of politics, economy, science, education, culture and health in Shanxi Province. It is also a comprehensive supporting reform demonstration area for the transformation of the national resource-based economy. The potential for the integration of 
the region and the development of the work resistant are small, and it is easy to form an integration force. Therefore, the circle is identified as the first integrated timing circle. Among the Blayer with Datong as the center, coal-related industries dominate, and the seven major coal groups in Shanxi, Tong Coal Group, Shanxi Coal Group, Luan Group, Yang Coal Group, and Jinneng Group, belong to this group. Several regions have made great contributions to the development of coal in the south and are typical resource-based regions. The development of professional logistics is better, and the infrastructure input factor (principal component 2) has a greater impact on this region, they are Datong $>$ Changzhi $>$ Jincheng $>$ Yangquan. The resource endowments make up for the insufficiency of economic development in a certain extent. At the same time good infrastructure will also promote the accelerated development of the comprehensive reform pilot zone for the transformation of the national resource-based economy in Shanxi Province. Therefore, it is determined as the second integrated timing circle. In the C-layer with Linfen as the center point, although coal is the pillar industry of Linfen, the Fenxi plain is the restricted development zone (the main producing area of agricultural products) as the "Principal Planning Area of Shanxi Province", agriculture is also an important industry that cannot be ignored. Yuncheng with characteristic agriculture as the pillar industry has many similarities with Linfen in the industry, and both cities are located in the Yellow Rivers Golden Triangle region of Shanxi, Shanxi, Hebei. Those two cities have common ground in industrial agglomeration and resource endowment. There is a certain scientific basis for the regions to be in the $\mathrm{C}$ circle, and it also has practical significance to consider this circle as the integration cycle of the third circle. In conclusion, the time sequence of spatial integration of Shanxi's regional logistics spatial integration is: A \{Taiyuan, Jinzhong, Xinzhou, Shuozhou, Lvliang\}> B \{Datong, Yangquan, Changzhi, Jincheng $\}>\mathrm{C}$ \{Linfen, Yuncheng $\}$.

\section{CONCLUSIONS AND RECOMMENDATIONS}

\section{A. Conclusions}

Based on the combination of principal component and twodimensional graph theory clustering, the time sequence of RLSI is studied. Some conclusions can be drawn:

- According to the time sequence of RLSI, in each circle, different types of logistics parks can be reasonably planned and configured to make use of the logistics industry space, to play a role in the evacuation effect of spatial agglomeration of the logistics industry. That can promote the development of Shanxi's regional logistics and realize the industrial upgrading.

- The time sequence of RLSI is as follows: A \{Taiyuan, Jinzhong, Xinzhou, Shuozhou, Lvliang\} B \{Datong, Yangquan, Changzhi, Jincheng $\}>$ C $\{$ Linfen, Yuncheng $\}$. The first sequential integration of the A conforms to the formation of the "sky-shaped" logistics channel and also meets the requirements for regional logistics space layout in the "Middle and long-term plan for the development of logistics industry in Shanxi Province (2015-2020)". At the same time, it also shows that due to the demand of social consumer goods and the influence of regional infrastructure investment, the spatial distribution of regional logistics shows obvious differences. From the Taiyuan, the center of the circle A, which has a relatively high level of economic development in the provincial center, it radiates $\mathrm{B}$ and $\mathrm{C}$ which the center points of the two circle are Datong and Linfen, to the north, southeast, and southwest respectively forming a logistics space hierarchy with the first the I-integration A demonstration, integrates the B and promotes the $\mathrm{C}$.

\section{B. Suggestions}

- The integration of the A circle ,Taiyuan, Jinzhong, Xinzhou, Shuozhou, and Lvliang, they are integrated with the industrial layout and planned, taking the Taiyuan-Jinzhong108National Road as the development principal axis, the spatial network of regional logistics was developed in turn using the Taiyuan highway main hub-Wusu cargo center as a demonstration area and functional expansion area, to make the spatial network layout of regional logistics is performed.

- The second-time sequence integration B circle layer \{Datong, Yangquan, Changzhi, Jincheng\}. Datong province serves as the Jinbei Coal Chemical Industry Base and the Yanmenguan Ecological Animal Husbandry Economic Zone. It has 4 national-level road freight hubs including Malianzhuang, Datang Road, Zhoushizhuang and Tashan. At the same time, it is also located in the Golden Triangle area of the Great Wall of Neimenggu, Shanxi, Hebei province. With Datong as the center point, Yangquan, Changzhi, and Jincheng were radiated to build coal distribution and transfer centers, coal coke logistics and warehousing and distribution centers, and special agricultural product spot trading markets.

- The third time sequence integration $\mathrm{C}$ circle layer \{Linfen, Yuncheng\} can be based on the Houma Road Freight Center (national level), actively integrate into the golden triangle in Shanxi, Shannxi and Hebei province and Yellow River, integrate coal transportation and reserve channels and reserve centers, rely on the features of transporting agricultural products in urban areas, and actively connect the construction of the Guanzhong Economic Zone and the Silk Road to create a commercial logistics channel.

\section{REFERENCES}

[1] H.J. L, Sasser.W.ESchlesinger, Service Valu eChain, Cambridg Harvard Business School Press, 1996, pp. 57-58.

[2] G. Avijit and M.L. Sara, Location Strategies for Re-tail and rvice Firms, Lexington: Lexington Books Press, 1987, pp.156 -158.

[3] P.Y.L. Becky, "Interplay of International,National and Local Factors in Shaping Container Port Development:A Case Study of Hong Kong," Transport Review, vol. 26(7), pp. 26- 37, 2001.

[4] P.A.T, "Peach of An Offer," Transportation \&Distribution, vol. 44(3), pp. 31-38, 2003.

[5] T. Eiichi and R.G. Thompson "Logistics Systems for Sustainable Cities," Amsterdam: Elsevier Press, 2004, pp.23- 59. 
[6] X.H. Chen and Q.G. Ye, "Regional Spatial Integration Research: Theoretical Evolution and Research Content," Journal of Chizhou College, vol. 20 (3), pp. 65-69, 2006.

[7] H. Zhang, B. Yu, and L.X. Ju, "Study on the Feature of Economic Space Agglomeration in Yangtze River Delta Based on GIS," Operations and Management, vol. 24(12), pp. 184-191, 2015.

[8] N.Z. Wang and Y.F. Shen. "Study on Spatial Distribution andEvolution Characteristics of Logistics in the Yangtze River Delta Region," Economic Geography, vol. 31(4), pp. 619-615, 2011. In Chinese

[9] S.D. Qi and J. Lei, "Study on the Regional Differences and Evolution of Regional Logistics in China's Silk Road Economic Belt," Arid Land Geography, vol. 34(1), pp. 217-226, 2016.
[10] Z.H. Fei, C.W. Shuai, H. Zhao, and D. Li. "Study on Time Series of Integration of Rural Residential Areas Based on Principal Component Analysis and Two-dimensional Graph Theory Cluster Analysis Take Bishan County of Chongqing Province as an Example," Regional Research and Development, vol. 33(1), pp. 93-97, 2014.

[11] S. Chen and T.W. Huang, "Study on the Spatial Distribution of Tourism Industrial Clusters in Hubei Province-Based on Two-Dimensional Graph Theory Clustering Method," Jianghan Forum, vol. 2012(5), pp. 54-56.

[12] L. Wang and J.J. Han, "Research on the Impact of Knowledge Management Based on the Growth of Logistics Enterprises on Performance Service InnovationPerspective," TechnologyManagement search, vol. 23, pp.149-161, 2014. 